\title{
Appendiceal Mucocele: A Particular Clinical-Pathological Entity
}

\author{
Taoufik Elabbassi ${ }^{1,2 *}$, Layla Elattar ${ }^{1}$, Amine Bachar $^{1}$ and Mohamed Rachid Lefriyekh ${ }^{1,2}$ \\ ${ }^{1}$ General Surgery Department, University Hospital Center Ibn Rochd, Casablanca, Morocco \\ ${ }^{2}$ Faculty of Medicine and Pharmacy, Hassan II University, Casablanca, Morocco
}

Submission: March 28, 2020; Published: April 07, 2020

*Corresponding author: Taoufik Elabbassi, Faculty of Medicine and Pharmacy General Surgery Department, University Hospital Center Ibn Rochd, Casablanca, Morocco

\begin{abstract}
Appendiceal mucocele is a rare disease, whose clinical symptoms resembles that of acute appendicitis, often diagnosed incidentally but can be asymptomatic. A correct preoperative diagnosis is very important in order to choose the right management and surgical tactic (appendectomy/ colectomy) to avoid dissemination and tumour recurrence.

We report the case of a 54-year-old woman, presenting intermittent right iliac fossa pain for 8 months in a context of apyrexia and whose abdominal CT scan revealed an appendiceal mucocele. The surgical act was a right hemicolectomy with postoperative follow-up without particularity.

Keywords: Appendiceal mucocele; Right hemicolectomy; Right iliac fossa; Appendectomy/colectomy; Appendix tumours; Mucinous tumours; Abdomino-pelvic Mass; appendicular neoplasm
\end{abstract}

\section{Introduction}

Appendiceal mucocele is a rare but well-known clinical and pathological entity with a non-specific symptomatology mimicking several common diseases. It is often detected as an incidental finding during surgery, routine radiological examination or endoscopic examination [1]. The clinical importance is reflected in the fact that it is often misdiagnosed and therefore various complications may occur due to inadequate detection/ management [2].

Appendiceal mucocele can be benign or malignant, whereas mucinous tumours account for 58\% of malignant appendix tumours [4]. Spontaneous or iatrogenic rupture of mucinous tumours of the appendix leads to spread to the peritoneum and viscera in the form of gelatinous material, resulting in a condition known as Pseudomyxoma Peritonei.

\section{Observation}

She is a 54 year old woman, without any particular pathological history, who presented intermittent pain in the right iliac fossa for 8 months, in a context of apyrexia, without any transit disorder or externalized digestive haemorrhage, without urinary signs, her general state was preserved, the abdominal examination found a slight sensitivity of the right iliac fossa, without palpable mass, the hernial orifices and the ganglion areas were free, digital rectal examination and vaginal examination were without particularities. The biological assessment showed haemoglobin of $11 \mathrm{mg} / \mathrm{dl}$, white blood cells of $7000 \mathrm{ele} / \mathrm{mm}^{3}$, and CRP of $7 \mathrm{mg} / \mathrm{l}$.

An abdomino-pelvic ultrasound found a mass with a cystic appearance at the expense of the appendix, or right ovary, without peritoneal effusion. The abdominal CT scan detected a very limited cystic formation of $8 \mathrm{~cm}$ long seems to be related to an appendiceal mucocele, the adnexa as well as the ovaries were normal (Figure 1).

Colonoscopy showed an extrinsic compression aspect of the cecal bottom. Tumor markers ACE and CA 19.9 were normal. The patient was operated by median laparotomy and surgical exploration revealed an $8 \times 5 \mathrm{~cm}$ appendix cystic mass, intact, without peritoneal effusion, carcinosis or detectable hepatic nodule. A right hemicolectomy was performed with omentectomy, and ileocolic anastomosis (Figure 2). The postoperative followup was uneventful. Histopathologic examination of the surgical specimen confirmed a low-grade mucinous appendicular neoplasm with total exeresis and no lymph node metastasis. 


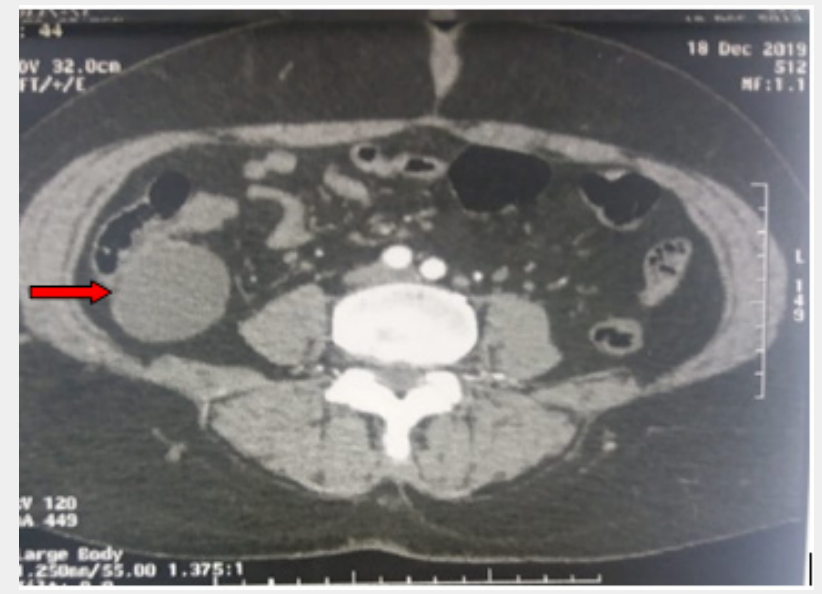

Figure 1: Cross-section of abdominal CT scan showing a cystic appendicular image suggestive of mucocele (red arrow).

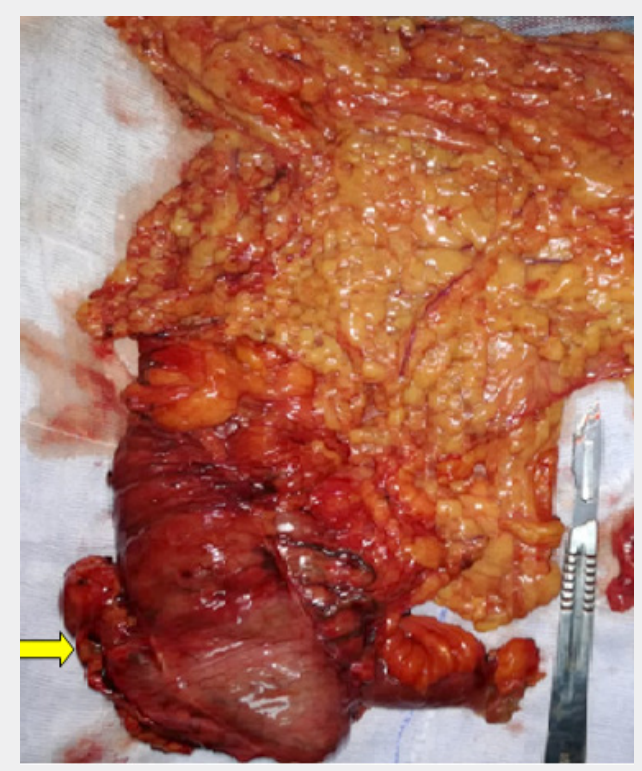

Figure 2: Image of the operative piece showing appendiceal mucocele (yellow arrow).

\section{Discussion}

Appendiceal mucocele is an uncommon affection accounting for 0.15 to $0.6 \%$ of appendectomies [4,5]. It affects preferably adults with an average age between 50 and 60 years [6,7], but can also affect children. It is a cystic dilatation of the appendix caused by the accumulation of mucus secretion intraluminally; this process is slow and progressive, without any sign of infection inside the organ. It results from obstruction of the appendix lumen, which is secondary to inflammatory or neoplastic proliferation of the appendix mucosa, or from lesions in the cecum adjacent to the appendix ostium. While some studies confirm its prevalence in females, others show a higher incidence in males [8]. The appendiceal mucoceles can be benign or malignant and WHO classifies them into four histological types: simple mucocele/ retention cyst, which has a normal epithelium and slight dilatation due to obstruction of mucus flow in the appendix. Hyperplastic epithelium, which has slight luminal distension. Mucinous cystadenomas, also known as low-grade mucinous appendicular neoplasms (LAMN), have epithelial atypia and moderate distension. Mucinous cystadenocarcinoma, which presents with invasion of the wall of the appendix, adds to the characteristics of LAMN [9]. Mucinous cystadenomas are the most common of the four types. Size is an important factor to consider, an appendiceal mucocele smaller than $2 \mathrm{~cm}$ is rarely malignant and those larger than $6 \mathrm{~cm}$ are more often associated with cystadenocarcinoma and a higher rate of perforation. Both benign and malignant 
ruptures are associated with pseudomyxoma peritonei, which are associated with significant morbidity and mortality [9]. Clinically, appendiceal mucocele is often asymptomatic, in about 50\% of cases it is discovered accidentally on radiological and endoscopic examination or during surgery [8]. The various clinical pictures that can be seen are a picture simulating, in the majority of cases, acute appendicitis generally leading to surgery from the outset but in these painful forms, the pain may be isolated and evolve in a subacute or chronic mode. Either the pseudotumour forms and the lesion presents as a mobile or fixed mass of the right iliac fossa or as an abdomino-pelvic mass, or the complicated forms of volvulus of the tumour mass, infection up to and including suppuration and perforation or rupture of the peritoneum $[10,11]$.

Abdominal ultrasonography remains the examination of choice for these clinical forms and may show a mass with small hypoechoic spots known as "onion skin" with a sensitivity of $83 \%$ and a specificity of $92 \%$ [12]. However, the CT scan is considered the most informative imaging method, as it can assess the relationship between peripheral organ formations, which can facilitate diagnosis. When the manifestations of CT are cystic structures closely related to the cecum with a round or long tubular shape, a thin cystic wall and a smooth contour, the possibility of mucinous adenocarcinoma of the appendix should be considered. The discovery of an appendicular cavity diameter greater than 13 $\mathrm{mm}$ raises a strong suspicion of mucinous appendicular neoplasm [11].

There is no radiological evidence to assert or exclude with certainty the malignancy of the underlying appendicular tumour, hence the indication for colonoscopy, which aims at a raised visible area in the coecum with an appendicular orifice located in its centre [10]. The final diagnosis always depends on histopathological examination of the resected tissue, and surgery is the only treatment with curative potential. During surgery, care must be taken to avoid rupture and spread of mucus or epithelial cells to the abdominal cavity, which can significantly affect patients' prognosis due to the high recurrence rate [12]. Simple appendectomy is the choice for patients with benign mucocele, as suggested by the presence of a normal cecum and appendix base with no evidence of perforation [13]. Right hemicolectomy is recommended when malignant mucocele is suspected by the presence of perforated mucocele, enlarged mesenteric lymph node or positive cytology or colonic invasion [1]. Accurate exploration of the abdomen is advised because of the well-known association between appendiceal mucocele and other mucin-secreting cell cancers, such as colon and ovarian cancers.

The reported incidence of Pseudomyxoma Peritonei is 65\% in cases of mucocele with perforation and $17 \%$ in cases of mucocele without perforation, therefore, for patients without perforation, the possibility of Pseudomyxoma formation cannot be completely excluded $[14,15]$.

\section{Conclusion}

Appendiceal mucocele is a rare tumour, which requires improved knowledge and understanding of this disease. Imaging has an important role in establishing the positive diagnosis on which surgical tactics, which may be limited to a simple appendectomy or right colectomy, depend. Confirmation remains histological, and the major concern is the transition to a Pseudomyxoma Peritonei, which requires the surgeon to handle the tumour mass carefully, avoiding intraoperative invasion.

\section{Consent}

According to the international or academic standard, patient consent was collected and retained by the authors.

\section{Ethical Approval}

As per international standard written ethical approval has been collected and preserved by the author(s).

\section{References}

1. Saad EA, Elsamani EY, Abd Elrahim, WE Elsiddig, KE Et Khalil EA (2018) Traitement chirurgical de la mucocèle de l'appendice: revue systématique et rapport de cas. Journal des rapports de cas chirurgicaux (6): 102.

2. Xu ZS, Xu W, Ying JQ, Cheng H (2017) Mechanical intestinal obstruction secondary to appendiceal mucinous cystadenoma: A case report and brief review. Medicine 96(5): e6016.

3. Ramaswamy V (2016) Pathology of mucinous appendiceal tumors and pseudomyxoma peritonei. Indian J Surg Onco 7(2): 258-267.

4. Padmanaban V, Morano WF, Gleeson E, Aggarwal A, Mapow BL, et al. (2016) Incidentally discovered low-grade appendiceal mucinous neoplasm: a precursor to pseudomyxoma peritonei. Clin Case Rep 4(12): 1112.

5. Pantiora EV, Massaras D, Koutalas J, Bagiasta A, Kontis EA (2017) LowGrade Appendiceal Mucinous Neoplasm Presenting as an Adnexal Mass. Case Rep Obstet Gynecol 2017: 7165321.

6. Mastoraki A, Sakorafas G, Vassiliu P, Contopoulou C, Arkadopoulos N (2016) Mucocele of the Appendix: Dilemmas in Differential Diagnosis and Therapeutic Management. Indian J Surg Oncol 7(1): 86-90.

7. Lansom J, Alzahrani N, Liauw W, Morris DL (2016) Cytoreductive Surgery and Hyperthermic Intraperitoneal Chemotherapy for Pseudomyxoma Peritonei and Appendix Tumours. Indian J Surg Oncol 7(2): 166-176.

8. B B SK, Jasuja P (2019,) Appendiceal mucocele-a rare case report. Int J Surg Case Rep 58: 21-25.

9. Motsumi MJ, Motlaleselelo P, Ayane G, Sesay SO, Valdes JR (2017) A case report of a giant appendiceal mucocele and literature review. Pan Afr Med J.28(1): 106.

10. Shiihara M, Ohki T, Yamamoto M (2017) Preoperative diagnosis and surgical approach of appendiceal mucinous cystadenoma: Usefulness of volcano sign. Case Rep Gastroenterol 11(3): 539-544.

11. Yang JM, Zhang WH, Yang DD, Jiang H, Yu L, et al. (2019) Giant lowgrade appendiceal mucinous neoplasm: A case report. World J Clin Cases $7(13): 1726$. 
12. Shubhada Dhage-Ivatury, Paul H Sugarbaker (2006) Update on the surgical approach to mucocele of the appendix. Journal of the American College of Surgeons 202(4): 680-684.

13. Fournier K, Rafeeq S, Taggart M, Kanaby P, Ning J (2017) Néoplasme mucineux appendiculaire de bas grade à potentiel malin incertain (LAMN-UMP): facteurs pronostiques et implications pour le traitement et le suivi. Ann Surg Oncol 24(1): 187-193.
14. Honoré C, Caruso F, Dartigues P, Benhaim L, Chirica M, et al. (2015) Strategies for preventing pseudomyxoma peritonei after resection of a mucinous neoplasm of the appendix. Anticancer research 35(9): 49434947.

15. Lynch K, Cho S, Andres R, Knight J, Con J (2016) Pre-operative identification and surgical management of the appendiceal mucocele: a case report. W V Med J 112(4): 28-31.

\section{Your next submission with JuniperPublishers will reach you the below assets}

- Quality Editorial service

- Swift Peer Review

- Reprints availability

- E-prints Service

- Manuscript Podcast for convenient understanding

- Global attainment for your research

- Manuscript accessibility in different formats

( Pdf, E-pub, Full Text, audio)

- Unceasing customer service

Track the below URL for one-step submission https://juniperpublishers.com/online-submission.php 